\title{
ENVELHECER NA INVISIBILIDADE: TEMPO E NARRATIVA NA PONTA OESTE DA ILHA DO MEL, PARANÁ, BRASIL
}

\author{
Eduardo Harder ${ }^{1}$ \\ Ana Elisa de Castro Freitas ${ }^{2}$
}

\section{Introdução}

No Brasil, grande parte das atuais unidades de conservação da natureza foi implementada a partir da década de 1990. A criação da Estação Ecológica da Ilha do Mel, através do Decreto Estadual n. 5.454/82, como Unidade de Conservação de Uso Indireto, situada na Baía de Paranaguá, litoral do Paraná, ocorre um ano após ser sancionada a Lei n. 6.902, de 27 de abril de 1981, que estabelece a modalidade conservacionista de Estação Ecológica no país (Paraná, 2013). Ao longo das décadas de 1980 e 1990, uma série de atos administrativos foram empreendidos pelo Estado brasileiro visando à desterritorialização e realocação das populações humanas existentes na Ilha do Mel, por força de lei (Derrida, 2010).

Em 2011, quando realizamos a sistematização dos dados populacionais que integram este trabalho, a coletividade de pescadores residente na Ponta Oeste era composta por 25 homens e mulheres que então possuíam uma idade média de 61 anos. Seu território articula-se na porção ocidental da Ilha do Mel, abrindo-se para a cidade de Paranaguá, onde residem os jovens.

Separados dos filhos pelas águas da baía e unidos aos mortos pela memória e por modos de criar, fazer e viver cotidianamente reinventados, os pescadores da Ponta Oeste empreendem o esforço de reconstrução de sua erfahrung/experiência (Benjamin, 1994), exercitando modos de narrar que revigorem os contornos coletivos da existência. Reconhecendo-se como parte indissociável da natureza do lugar, recorrem à figura de um direito de natureza em ali permanecer.

\footnotetext{
${ }^{1}$ Universidade Federal do Paraná, Brasil.

${ }^{2}$ Universidade Federal do Paraná, Brasil.
} 


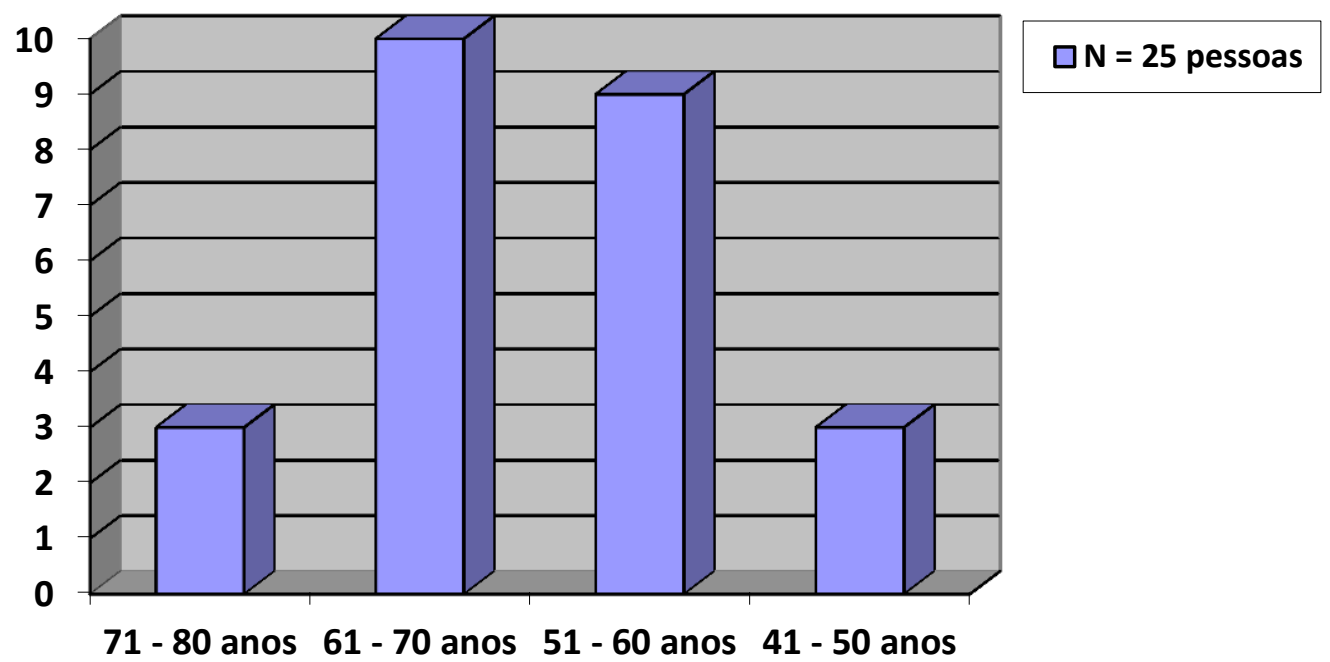

Figura 1: População de moradores da Ponta Oeste (2011) por faixa etária.

O que se irá analisar no presente artigo é o esforço desta coletividade em manter sua territorialidade centrada na Ponta Oeste da Ilha do Mel e os mecanismos adotados pelo Estado brasileiro para desterritorializá-la do local.

\section{As margens do tempo: viver e reviver entre as águas do mar}

Estávamos no centro da cozinha de uso comum da Ponta Oeste. No movimento das mulheres, entre o fogão à lenha e o manejo dos utensílios, pulsava um sentido de vida, propagado nos aromas dos temperos e da carne salgada dos peixes e frutos do mar, empanada cuidadosamente em farinha de mandioca. Na madrugada daquele mesmo domingo, os barcos e redes haviam-se lançado na baía de Paranaguá em busca das iguarias que Dircéia, Leonor e Leonir então preparavam.

Chegamos à Ponta Oeste trazidos pelo barco dos irmãos Zoel e Almir Pereira, em uma travessia de cerca de 30 minutos que liga Pontal do Paraná à porção ocidental da Ilha do Mel. Havíamos sido convidados para um almoço de domingo, após uma temporada de chuvas que dificultaram nosso acesso à Ponta Oeste.

No exercício da docência no Setor Litoral da Universidade Federal do Paraná, desde 2007 o caso da Ponta Oeste tem nos instigado reflexões no campo das assim denominadas problemáticas socioambientais. Desassossegado, nosso olhar procura nas entrelinhas do viver daqueles pescadores uma perspectiva que transcenda a análise dos conflitos entre o Estado e as chamadas populações tradicionais, quando o que está em 
jogo são ordenamentos territoriais informados por uma mentalidade conservacionista e patrimonialista, centrada na noção de natureza intocada (Diegues, 1996).

Sem desconhecer o conflito entre as lógicas da tradição e da modernidade, evitamos cair nas armadilhas de uma análise socioambiental de caráter universalista, que coleciona casos destituídos de existência, e buscamos qualificar a situação da Ponta Oeste no real/concreto que advém do campo da experiência (Benjamin, 1994).

Nossos primeiros contatos com as famílias da Ponta Oeste ocorreram durante um encontro promovido pelo Instituto de Terras, Cartografia e Geociências do Paraná (ITCG), em Curitiba. Na ocasião, a Sra. Dircéia Pereira de Souza, natural da Ponta Oeste, buscava acessar um relatório técnico assinado pelo Procurador Jurídico do Instituto Ambiental do Paraná (IAP), Sr. Hélio Dutra.

Passados quase dez anos, o documento até hoje não foi localizado e permanece obscuro no campo processual. Segundo a Sra. Dircéia, tratava-se de um relatório com parecer favorável à permanência das famílias de pescadores na Ponta Oeste, dissonante com os diversos documentos emitidos pelo mesmo IAP.

Neste breve encontro, Dircéia relatou que a coletividade da Ponta Oeste enfrentava sérias dificuldades de permanência em seu território, em função das ações reiteradas do Estado do Paraná, voltadas à manutenção da Estação Ecológica da Ilha do Mel, principalmente por atos da administração local do órgão ambiental.

Embora conhecêssemos a Ilha do Mel há mais de vinte anos, a situação da Ponta Oeste nos era completamente nova. Invisível nos roteiros turísticos, tampouco presente nas cartografias ambientais, o interesse pelo espaço de vida daquela coletividade nos mobilizou a procurar nas entrelinhas dos discursos oficiais sua história à contrapelo (Benjamin, 1991, 1994), e iniciamos um estudo etnográfico e jurídico, voltado ao reconhecimento dos pescadores que integram esta coletividade.

A primeira visita à Ponta Oeste ocorreu após duas semanas, em reunião promovida pela coletividade na sede da Associação dos Nativos e Pescadores da Ponta Oeste, com a presença de quase vinte pessoas, ainda em 2007. Ali, sob o telhado de fibra de guaricana ${ }^{3}$ trançada, descortinou-se um universo que viria, nos próximos anos, revestir-se de grande densidade e intensidade (Harder, 2014).

\footnotetext{
${ }^{3}$ A palmeira guaricana (Geonoma schottiana Mart) é uma espécie de pequeno porte, típica do sub-bosque de áreas com grandes índices pluviométricos. Abundante no sul do Brasil é tradicionalmente utilizada pelas populações costeiras para a confecção de coberturas das casas, possuindo elevado grau de vedação às chuvas.
} 
Quem iniciou o diálogo foi o Sr. Ivo Pereira, o mais velho dos oito irmãos Pereira, na época, com 76 anos de idade. Em sua fala rica em metáforas, Sr. Ivo lançou uma imagem e uma pergunta que nos instigaram uma série de outros questionamentos: "Há uma muralha que está em volta da Ponta Oeste e nos torna invisíveis. Por que há essa muralha?".

Os irmãos Pereira, articulados por laços de afinidade às famílias Rodrigues, Batista, Silva, Cordeiro, Fernandes, Malaquias, entre outras, constituem o centro da territorialidade atual da Ponta Oeste.

Na memória coletiva, o pai Arthur Gomes Pereira e o avô Agostinho Pereira são referidos como naturais do local. O Sr. Arthur, em especial, é reconhecido por ter desempenhado papel central na interlocução com as instituições estatais, tais como a Capitania dos Portos e a prefeitura municipal de Paranaguá. Por outro lado, é reconhecido pelo repertório de conhecimentos e práticas associados à cura e ao domínio da farmacopéia de origem animal, mineral e vegetal, vinculada às paisagens da Ilha e regiões adjacentes.

A Carteira de Registro de Pesca de Arthur Gomes Pereira informa que ele nasceu na Ponta Oeste em 4 de julho de 1908. O Sr. Agostinho Pereira, por sua vez, teria nascido na Ponta Oeste entre 1870 e 1880, segundo relato de seus netos.

$\mathrm{Na}$ perspectiva do Sr. Ivo Pereira, a imagem de continuidade com seus antepassados é acionada para reafirmar o vinculo territorial com a Ponta Oeste. Num outro sentido, a metáfora da "muralha" - vivenciada na invisibilidade da experiência contemporânea - contrapõe-se à figura da liberdade de outros tempos: "Nasci na Ponta Oeste, como meu pai, meu avô, meu bisavô. Essa vida sempre foi de dificuldade, mas com liberdade" (Ivo Pereira, 2007).

A ausência crescente de liberdade é associada aos impactos da relação com o Estado brasileiro. Trata-se de uma relação de controle, na qual as razões de Estado se sobrepõe de diferentes formas às lógicas desta e de outras coletividades tradicionais da região. Sobre o exercício livre da pesca, por exemplo, tal razão de Estado incidiu com o controle, desde o início do século XX, expresso na exigência de registro, atualização e manutenção de Cadastros de Pesca junto à Marinha do Brasil. 

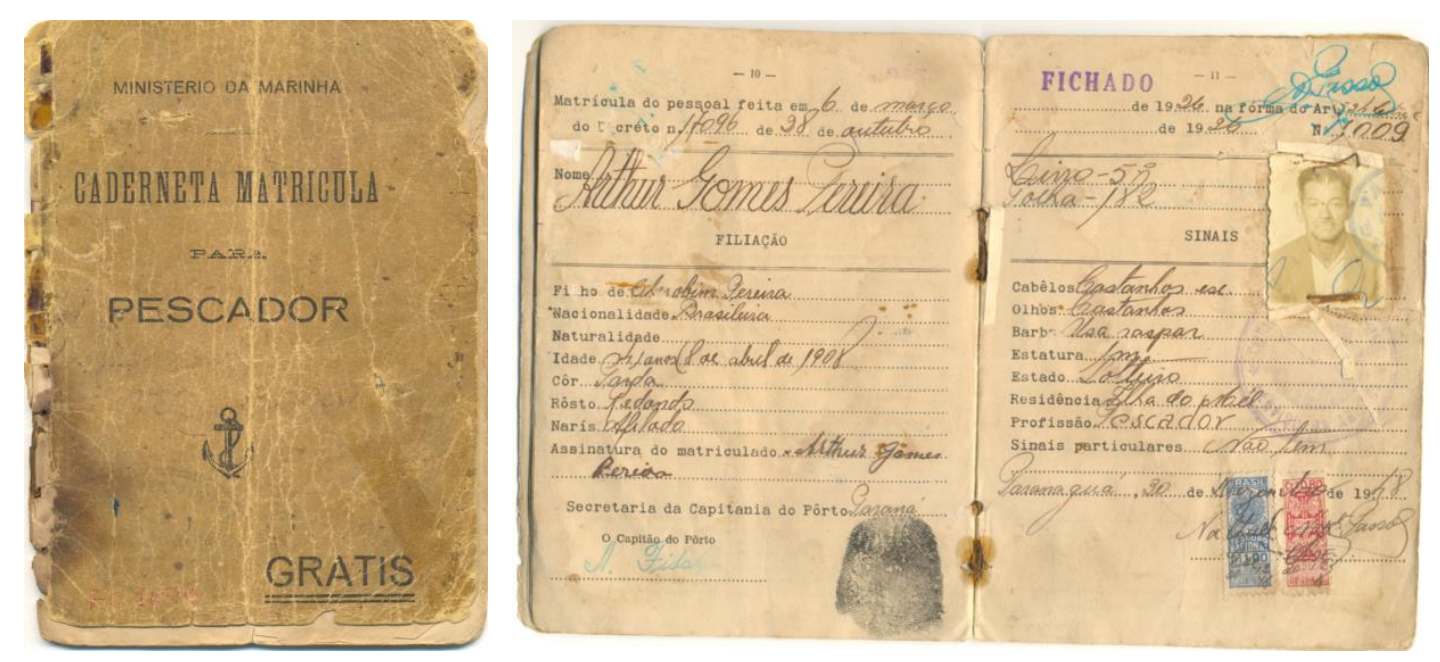

Figura 2: Carteira de Pesca de Arthur Gomes Pereira.

Uma constelação de memórias emerge quando os nativos e pescadores da Ponta Oeste da Ilha do Mel encontram espaço e tempo para narrar sua história e sua experiência. Durante os primeiros anos da década de 1940, referem os impactos da Segunda Guerra Mundial na região. Sr. Ivo Pereira relata que estes anos foram marcados pela proibição de iluminação das casas na Ilha do Mel. As noites eram então iluminadas pela luz do luar, sendo vedado mesmo o uso de lamparinas, sob risco de prisão, acaso alguma família fosse flagrada com iluminação. Recorda que houve, certa vez, uma advertência do Capitão Militar às famílias, seguida da ameaça de encarceramento, acaso a transgressão persistisse.

Um pouco antes, na década de 1930, há a memória da construção das instalações da prisão na Ilha das Cobras, muito próxima da Ponta Oeste, e a proibição de pesca nas proximidades. A Sra. Leonor Gomes Pereira Cordeiro relata que nos tempos de sua infância e juventude havia na corrente marítima próxima à Ilha das Cobras a presença constante de uma espécie de tubarão de pequeno porte, localmente conhecido como "tintureira". Embora relativamente pequeno, o "tintureira" possui considerável grau de agressividade, e representava perigo aos que se aventurassem a nadar no local. Mesmo assim, foragidos do cárcere da Ilha das Cobras eram eventualmente encontrados pelas famílias da Ponta Oeste e o senhor Arthur Gomes Pereira tinha a incumbência de notificar o fato às autoridades. 
Entre os anos de 1930 e 1940 a crescente implementação de atividades mercantis nos Portos de Paranaguá e Antonina foi sentida pelas famílias da Ponta Oeste, com a intensificação da utilização do Canal do Norte, que servia de acesso a grandes embarcações que se dirigiam a esses portos. No entanto, tal impacto foi significativamente amplificado a partir da mudança do acesso do Canal do Norte para o Canal da Galheta, na década de 1970, resultando na modificação da composição específica das comunidades de peixes e na redução da densidade populacional das espécies preferenciais para a pesca na Ponta Oeste.

A narrativa dos pescadores refere que neste período iniciou o processo de drástica redução local de algumas espécies da ictiofauna, que hoje atinge seu auge, diante da intensificação das atividades portuárias. Jamais houve qualquer compensação pelos impactos na pesca por parte do Porto de Paranaguá.

Nas coletividades tradicionais litorâneas do sul, a pesca está associada a um regime de mutirões - modalidade coletiva de produção que conecta atividades no mar com atividades na terra (Diegues, 2004). Na Ponta Oeste, há o relato de que entre os anos de 1965 e 1970 houve abundância de pescados e que, em 1970, oito famílias de pescadores vieram da Ilha de Superagui para residir na Ponta Oeste. Dessa mesma época, há o relato dos últimos grandes mutirões para o plantio de mandioca, melancia, melões, abóboras, etc.

Associados a estes mutirões, ocorriam manifestações festivas envolvendo música e dança, registradas no litoral do Paraná como uma modalidade de fandango caiçara. No fandango caiçara, o dono da roça oferece aos colaboradores que participam do plantio ou da colheita uma paga que consiste em confraternização festiva com alimentos e bebidas, dança e música.

O fandango caiçara envolve a fabricação de instrumentos musicais e elementos da indumentária cultural, artesanalmente produzidos, tais como a rabeca e o tamanco, ambos confeccionados a partir do manejo da madeira de caixeta. Arte, cultura, sociedade e natureza se articulam no fandango caiçara, conferindo-lhe o status de manifestação de importância central na reafirmação dos laços de reciprocidade entre as famílias que compartilham de uma mesma ecologia. 
A inauguração e utilização do Canal da Galheta, como via de acesso aos portos de Paranaguá e Antonina, na década de 1970, é atribuída como responsável pelo primeiro grande fluxo migratório da Ponta Oeste para outras localidades. Nesses anos, segundo relatos atuais, havia cerca de 80 (oitenta) famílias presentes na Ponta Oeste.

O controle do Estado sobre as pessoas da Ponta Oeste ganha novos contornos a partir do ano de 1980, quando foi empreendido o "Levantamento Populacional e de Edificações Existentes", através do instrumento de cadastro e registro dos moradores locais ${ }^{4}$, dois anos antes do ato de criação da Estação Ecológica da Ilha do Mel. Pode-se considerar que, ao lado das cartografias, os cadastros e registros, seja sob a forma de censos ou de inventários dirigidos, são mecanismos efetivos de controle estatal sobre populações e suas territorialidades (Foucault, 1999).

No ano de 1980, esse registro e cadastro da população local da Ponta Oeste foi realizado sob a coordenação da Secretaria de Patrimônio da União (SPU), sendo executado por uma moradora de outra localidade da Ilha do Mel, referida pela Sra. Leonor Gomes Pereira Cordeiro pelo nome de Cidinha.

O "Levantamento Populacional e de Edificações Existentes" trouxe um conjunto de informações relevantes para a compreensão do atual cenário da Ponta Oeste, em especial, e da Ilha do Mel como um todo.

Por ocasião do cadastro, a coletividade da Ponta Oeste possuía o maior número relativo de habitantes da Ilha do Mel: 211 pessoas. As outras 05 localidades contavam com os seguintes números de habitantes: Prainha (204), Nova Brasília (90), Farol (60), Praia Grande e do Miguel (25) e Fortaleza (16), que somando com a Ponta Oeste totalizavam 606 habitantes (ITCF, 1980). Ou seja, em 1980, mais de 1/3 da população da Ilha do Mel estava na Ponta Oeste.

No que se refere às edificações presentes, além de uma escola (somente Prainha e Nova Brasília também contavam com estas estruturas), a Ponta Oeste registrava neste período 43 edificações, sendo 39 de moradores e apenas uma residência de veranista. Nova Brasília, por exemplo, de um total de 49 edificações, contava com 18 casas de moradores e 24 de veranistas; Prainha, de um total de 82 edificações, 39 eram de moradores locais e 22 de veranistas.

\footnotetext{
${ }^{4}$ Ilha do Mel, Levantamento populacional e edificações existentes. Comissão Especial de Levantamento de Campo, dezembro de 1980, Secretaria do Patrimônio da União.
} 
Outro dado interessante acessível neste documento é o do número de habitantes por residência, cuja média da Ponta Oeste, neste período era de aproximadamente 05 pessoas em cada moradia, chegando a haver registro de 11 pessoas compartilhando uma mesma casa, o que contrasta com os dados das demais localidades. Cabe ressaltar que nesta época estava sediada na Ponta Oeste a única Zona Eleitoral da Ilha do Mel, uma escola, duas igrejas e 02 dos 09 estabelecimentos comerciais da Ilha.

Quanto à composição etária da população, o cadastro de 1980 informa dados de grande interesse para nosso estudo, relativos ao número de crianças por localidade neste período: na Ponta Oeste havia 87 crianças entre 0 e 14 anos, na Prainha 83 crianças, em Nova Brasília 37, no Farol 21, na Praia Grande e do Miguel 05 e na Fortaleza 04 (ITCF, 1980).

Este retrato da Ponta Oeste em 1980 evidencia uma coletividade composta essencialmente por população local, com apenas uma residência edificada por veranista na área. Além disso, $41 \%$ da população situava-se na faixa etária entre 0 e 14 anos, o que demonstra um perfil jovem de população, e facilita a compreensão das narrativas que retratam este como um tempo de alegria, liberdade, abundância e futuro.

A partir de 1982, e sem que pudessem construir uma compreensão exata das motivações que levaram o estado do Paraná a criar, por meio do Decreto n. 5.454/82, a Estação Ecológica da Ilha do Mel, com área de 2.240 hectares e 69 ares, os moradores da Ponta Oeste narram uma sequência de fatos que culmina, em 1985, com o início do processo de migração forçada de parte das famílias para a cidade de Paranaguá, e que perdurou até 1992.

Num primeiro nível narrativo, esse processo migratório é associado à escassez da pesca, reduzida ano a ano, em função dos impactos diretos vinculados à intensificação do fluxo de embarcações de grande porte, e à ausência de políticas públicas voltadas à melhoria nas condições de vida. O grupo escolar, por exemplo, instalado em 1967 na casa de madeira de um dos moradores e transferido em 1985 para uma escola de alvenaria construída pela Prefeitura Municipal de Paranaguá, ofertava somente o ensino de $1^{\mathrm{a}}$ a $4^{\mathrm{a}}$ séries, não atendendo às necessidades da população jovem. No início da década de 1990 mesmo esta escola seria fechada.

De acordo com o Sr. Ivo Pereira, a notícia da criação da Estação Ecológica em 1982 não produziu de imediato uma mudança significativa na vida cotidiana do grupo, posto que o ato de criação não foi acompanhado de um esclarecimento consistente que 
lhes permitisse a apreensão dos sentidos territoriais que somente a experiência histórica, nos anos seguintes, lhes garantiu.

De modo concatenado, o Estado produziu o cercamento da área de uso da coletividade, com a colocação de marcos de divisa delimitando os 31,7763 hectares da “zona de ocupação", nos termos do Relatório n. 2, de julho de 1981, confeccionado pela Comissão Especial para Estudo das Ilhas do Litoral Paranaense, que definiu o primeiro Plano de Uso para a Ilha do Mel. Observe-se que o acesso a esses documentos oficiais só se deu a partir da década de 1990, quando a Sra. Dircéia Pereira de Souza começou sua peregrinação pelos órgãos estatais, em busca de dados que juntassem esse conjunto de fatos, até então desconexos na perspectiva do grupo.

Foi somente com as ações deflagradas pelo extinto Instituto de Terras, Cartografias e Florestas (ITCF), entre 1986 e 1988, que a coletividade da Ponta Oeste percebeu que os tempos estavam mudando.

O fato que efetivamente demarca duas temporalidades na narrativa construída pelas famílias é a proibição do cultivo das roças, coerção materializada em um ato de violência simbólica recorrentemente lembrado: o corte de um conjunto específico de pés de café, cujas mudas eram cuidadosamente mantidas há gerações, e cuja fenologia marcava o tempo da vida da coletividade. A floração, a frutificação, o cuidado, a colheita, a reciprocidade social em torno do café, conferia uma duração própria ao ritmo cotidiano, operando como um calendário vivo na Ponta Oeste.

O corte violento dos pés de café, pelos agentes de Estado, é um fato sombrio na memória da coletividade, e opera como divisor simbólico de duas temporalidades: o tempo da liberdade e o tempo da invisibilidade produzida pelo pela elevação da muralha, metáfora tantas vezes mencionada pelo Sr. Ivo Pereira em nossas conversas.

A partir da década de 1990, uma mudança foi sentida, no que se refere aos processos de saída de famílias da Ponta Oeste. Houve então um estímulo claro de parte do Estado, voltado à remoção de pessoas da Ponta Oeste para outras localidades da Ilha do Mel. Quatro famílias foram removidas para Nova Brasília. Nos anos seguintes, as famílias de Pedro Alves, Faustino dos Santos (ex-presidente da Associação dos Nativos e Pescadores da Ponta Oeste), entre outras, foram deslocadas para Nova Brasília.

Às famílias que permaneceram na Ponta Oeste, transpareceu enfim, com toda a sua força, o sentido dado pelo Estado às normativas voltadas à conservação da natureza, noticiadas dez anos antes, sem maiores esclarecimentos. 
Para quem ficou, as restrições foram se tornando cada vez mais severas, sob três formas: controle através de cadastros dos moradores, indeferimentos reiterados de reforma e construção de moradias e autuação por crimes ambientais, inclusive com episódios de tentativa de prisão das mulheres. Há processos criminais ainda em trâmite envolvendo pessoas da Ponta Oeste.

Este conflito socioambiental é percebido e narrado pelo Sr. Ivo Pereira, em entrevista aos autores:

O IAP nos impõe uma escravidão. É desumano o que é feito aqui. (...) Eles não podem tirar o povo daqui. Então eles vêm oprimir. (...) Antes de isso aqui virar ecologia, nós já estávamos aqui (...) Há um casal que foi proibido duas vezes de fazer o banheiro (...) Minha casa é aquela ali. O IAP já veio aqui para derrubar a casa. A primeira casa eu construí em 1953. Em 1975 precisei fazer uma reforma e a Capitania dos Portos autorizou. Em 1990 eu precisei fazer três requerimentos e eles foram indeferidos. Depois foram feitos 11 (onze) requerimentos da comunidade, e eu tive meu requerimento aceito. (Ivo Pereira, entrevista, 2011).

As restrições territoriais a que estão submetidas as famílias da Ponta Oeste, resultaram em novas condutas territoriais (Little, 2002), associadas à expansão do território existencial desta coletividade, que hoje abarca, a partir da Ponta Oeste, a cidade de Paranaguá e outras localidades da Ilha do Mel.

Atualmente as novas gerações encontram dificuldades de consolidar um sentimento de pertencimento à Ponta Oeste. Além da precariedade das habitações, cujos pedidos de reforma são reiteradamente indeferidos, não há energia elétrica e existem restrições de acesso às fontes de água potável.

As novas gerações querem estar [na Ponta Oeste], só que a dificuldade é que não tem escola. A escola fechou em 1993. Então não tem escola e eles têm que estudar em Paranaguá. Porque se for para Nova Brasília é difícil também, então já fica em Paranaguá. As famílias estão divididas. Os pais ficam na Ponta Oeste, dependem para tirar o sustento dali e os filhos em Paranaguá. Nos finais de semana e nas férias as crianças estão sempre por ali. (Dircéia Gomes Pereira, entrevista, 2011)

[Penso em] uma melhora, não para mim, mas para a localidade. Para esses pescadores que estão justamente com os pés enrugados de viver a vida deles mais na água, no sol, na chuva e no frio. Estão aí muitas vezes sem aqueles meios de ter aquela liberdade até mesmo para fazer um banheiro dentro de casa. Passa a acontecer isso que vocês estão vendo, tem família que está aí, vivendo debaixo de um barraco, de uma lona. Então, com a privação aqui não tem mais aquela liberdade. A gente não quer liberdade para avançar no mato. Não, não é isso não. Nós queremos liberdade, como se diz, para viver uma vida tranquila. Que é o que a gente deseja para esses homens que estão agora na meia idade e tem filhos para dar de comer. Não é? Eles precisam dar de comer e eles vem aqui buscar o sustento para eles e para os filhos que ficaram lá para estudar. Então eles estão repartindo, como 
se diz, a família, o casal de velhos que precisa buscar o alimento de cada dia. (Ivo Pereira, entrevista, 2011)

Eu espero um futuro melhor. Renovar novamente a localidade. Isso é importante. Que a família deseje morar aqui e gostem. (João Batista Castanho, reconhecido por todos como o professor da Ponta Oeste, iniciou a docência em 1959. Seus pais vieram da Ilha de Superagüi em 1953 e é casado com Maria Pereira Batista, natural da Ponta Oeste da Ilha do Mel. Entrevista, 2011)

Como resultado, a população residente foi gradativamente envelhecendo e seu esforço intensificou o trânsito entre a Ponta Oeste e a cidade de Paranaguá, onde residem filhos e netos, dando origem a uma territorialidade em mosaico (figura 3).

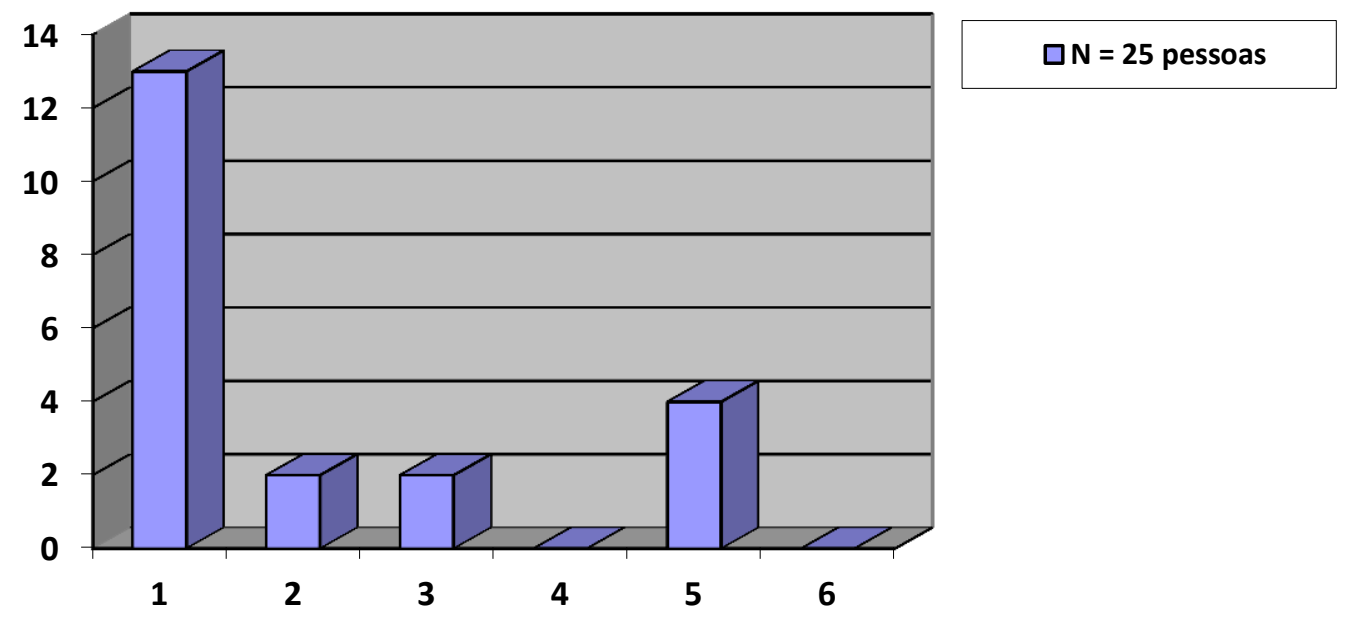

Legenda:

1 = Homens sozinhos, cuja esposa e/ou filhos residem na cidade de Paranaguá;

2 = Homens sozinhos sem esposa e/ou filhos;

3 = Mulheres sozinhas, cujo esposo e/ou filhos residem na cidade de Paranaguá;

4 = Mulheres sozinhas sem esposo e/ou filhos;

5 = Casais, cujos filhos residem na cidade de Paranaguá;

$6=$ Casais sem filhos

Figura 3: Territorialidades da população residente na Ponta Oeste em 2011.

A manutenção da vida, em constante diáspora, é agravada pelas crescentes dificuldades de navegação nas águas da baía, cujo território é atualmente dominado pelo intenso fluxo de cada vez maiores navios mercantes que se dirigem ao porto.

O movimento das pequenas embarcações pesqueiras exige aos seus condutores conjugar, aos tradicionais conhecimentos sobre a lua, as marés, os ventos, aqueles referentes à ciência da oportunidade, relativa às dinâmicas portuárias. Trata-se de um 
novo conjunto de saberes relacionados às interfaces na relação com o porto de Paranaguá e sua ecologia.

Muitas vezes os navios trafegam com velocidade superior à permitida para um deslocamento nas águas internas da baía de Paranaguá. Tal fato já foi presenciado durante os trabalhos de campo realizados na Ponta Oeste.

A passagem dos navios pelo Canal da Galheta, tangenciando o território marinho da Ponta Oeste, resulta em forte movimento das águas do mar, mensurável no súbito avanço e recuo da maré na praia que margeia a localidade.

Ao ser indagado sobre a técnica de equilíbrio em sua canoa utilizada para a pesca artesanal, quando ocorre o encontro com as ondulações do mar provocadas pela passagem dos navios, o Sr. Laurival Siqueira responde com costumeiro bom humor e largo sorriso: “Ah, isso é fácil! Posso ensinar a permanecer de pé quando passa um navio. Depois de alguns dias, você vai aprender a segurar a rede com uma mão e a marmita com a outra...”.

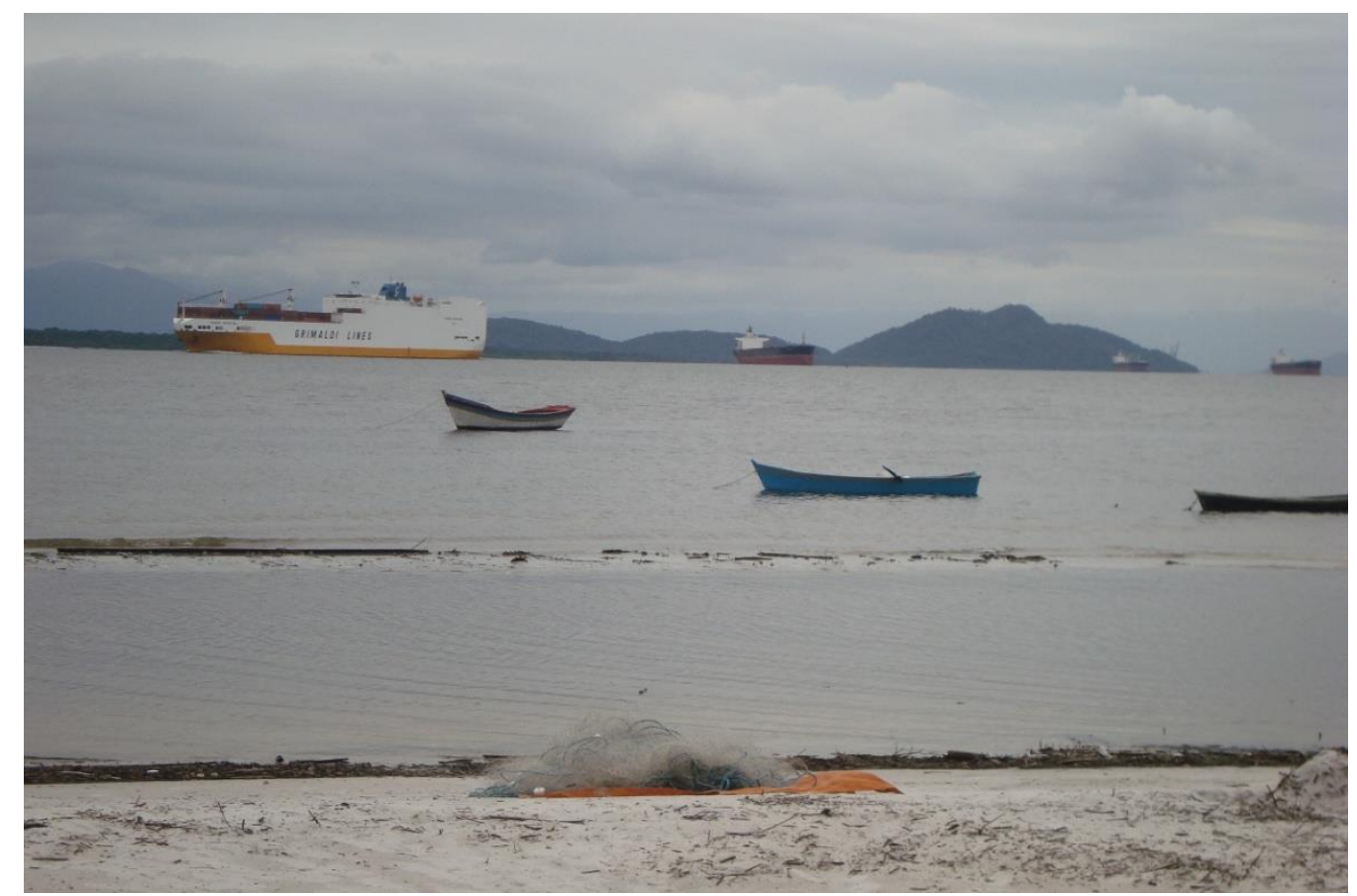

Figura 4: Navios mercantes no horizonte, vistos desde o ancoradouro de canoas na Ponta Oeste da Ilha do Mel.

Fotografia: Ana Elisa de Castro Freitas. 
No entorno do núcleo urbano de Paranaguá, entre as águas de sua baía, centenárias coletividades localizadas em ilhas e no continente estabelecem sua relação com esta cidade colonial. Os fluxos de circulação são propiciados precisamente pelas pequenas embarcações, tecendo a vasta rede das relações de reciprocidade entre as pessoas, com a comercialização do pescado, o acesso aos serviços públicos, as visitas a parentes, o manejo do território, etc.

A área de influência direta do porto de Paranaguá abarca e impacta o território destas coletividades em toda a extensão da baía e seu entorno, desde o instante em que diariamente dezenas de navios aguardam uma autorização para atracar no cais ${ }^{5}$.

O porto de Paranaguá ingressou nos circuitos de difusão globalizada de mercadorias. Seu espaço, cada vez mais racionalizado, tem significado a precarização da mão de obra local composta pelos trabalhadores da estiva ${ }^{6}$ e o arrendamento de largas parcelas do cais a grandes conglomerados econômicos, cujo poder de decisão expressa interesses de cooperativas agroindustriais, empresas de logística marítima, usinas de cana de açúcar, produtores de fertilizantes agrícolas, entre outros, articulados a empresas e instituições de capital internacional.

O incremento das atividades portuárias foi estimulado, desde as décadas de 1960 e 1970 com a mudança do Canal do Norte para o Canal da Galheta para o acesso dos navios ao cais do porto e também com a inauguração da rodovia federal BR-277, ligando o litoral às demais regiões do estado, em substituição à sinuosa Estrada da Graciosa.

Tais fatos ocorreram em uma conjuntura de expansão das fronteiras agrícolas voltadas à produção de novas commodities internacionais como soja, trigo, milho, etc., reconfigurando a relação de um espaço e tempo até então forjados na mobilidade de bens e também pessoas. As inter-relações de um mundo global, conectado em redes de

\footnotetext{
${ }^{5}$ A coletividade Mbyá Guarani da Terra Indígena Jacutinga, Ilha da Cotinga, por exemplo, relata a morte de um de seus membros por afogamento, em episódio que envolveu o naufrágio de três pequenas embarcações artesanais que faziam o percurso entre a ilha e a cidade de Paranaguá, em virtude das vigorosas ondas produzidas pelo tráfego de grandes navios e embarcações de apoio que se deslocavam nas águas da baía. A memória desse naufrágio está relacionada hoje com a redução da autonomia na mobilidade Mbyá na porção aquática de seu território local. A técnica de construção e uso de embarcações entre os Guarani hoje está restrita a poucos membros da coletividade e não é mais assunto de todos. (Freitas, 2010).

${ }^{6}$ É comum o relato entre os membros da coletividade da Ponta Oeste do trabalho que intercala períodos em que são contratados como estivadores do porto com outros em que há a preponderância da pesca artesanal.
} 
comércio, trouxe aos portos uma conotação especial, a de centros nervosos de um complexo sistema de circulação de mercadorias.

Paralelamente, o processo de privatização da infraestrutura pública, ocorrido principalmente a partir de meados da década de 1990, acarretou em um amplo domínio privado do acesso à cidade de Paranaguá e ao porto, seja por meio das vias férreas da antiga Rede Ferroviária Federal (RFFSA), da rodovia federal BR-277 ou das cartas de concessão para utilização do cais do porto e, portanto, do acesso ao mar.

Nas constantes dragagens necessárias para manter a profundidade compatível com o deslocamento de navios cada vez maiores, a constante agitação do fundo da baía tem significado a drástica alteração na ecologia marinha da região, com forte impacto socioambiental $^{7}$. A narrativa local refere a extinção de algumas espécies da ictiofauna, além do quase desaparecimento de golfinhos e camarões, os quais integravam o repertório de espécies apreciadas e companheiras de pesca.

(...) de uns tempos para cá se o pescador vai soltar a sua rede e pega cinco ou seis quilos de peixe, fica feliz. Inclusive agora, com a dragagem, o que chegou de peixe decapitado, sem as nadadeiras... A qualidade do peixe ainda tem, mas tem espécies de peixes que não existem mais. Quando, agora, com essa dragagem do Canal, chegaram esses peixes decapitados, o pessoal tirou foto e tudo o mais. Daí teve uma oficina na Nova Brasília. Nós fomos nessa oficina, que é feita pela empresa que faz a dragagem. Estivemos lá e mostramos as fotos para o pessoal. No final das contas, ali depois a guria [responsável pelas ações de dragagem] já não conseguiu mais essas fotos, que sumiram e se perderam. Ficaram perdidas no tempo... (Dircéia Gomes Pereira, entrevista, 2011)

Em síntese, o processo migratório que atingiu a coletividade da Ponta Oeste também é associado à escassez da pesca, reduzida ano a ano em função dos impactos diretos vinculados à intensificação do fluxo de navios de grande porte e à ausência de políticas públicas voltadas à melhoria nas condições de vida das pessoas. E não há, até este momento, qualquer forma de compensação pelos impactos na pesca artesanal causados pelas atividades portuárias desenvolvidas pelo Porto de Paranaguá e sob responsabilidade da Administração dos Portos e Paranaguá e Antonina (APPA), uma autarquia criada em 1947 pelo governo paranaense.

\footnotetext{
${ }^{7}$ A coletividade da Ponta Oeste apresentou um relato sobre a situação desencadeada pelas constantes dragagens do porto ao Ministério Público do Estado do Paraná, em sua sede de Paranaguá, no mês de dezembro de 2012, quando foram questionados sobre os impactos socioambientais resultantes da atividade portuária.
} 
O Sr. Laurival Siqueira resume, em poucas palavras, um sentimento comum diante dessa conjuntura: "A vida do pescador tem que ser um pouco mais privilegiada para nós, não é? Nós estamos muito sacrificados, sabe? E ninguém liga para nós. (...) É igual passarinho voando: tá pra lá, tá pra cá. Levanta e nada dá certo...”

\section{Lembranças e silêncios}

Em suas considerações sobre o tempo futuro, as pessoas da Ponta Oeste acionam a perspectiva de envelhecer em paz e a esperança no retorno das novas gerações. Simultaneamente, percebe-se um esforço da família Pereira na produção de uma narrativa que encontre interlocutores, dissolvendo a "muralha da invisibilidade", e que possibilite a conexão de sentido entre a experiência dos velhos da Ponta Oeste e aquela que seus jovens estão construindo.

Se a relação com o Estado, ao longo das últimas três décadas, produziu ruínas do ponto de vista da cultura material e imaterial (Benjamin, 1986, 1994), sobressaem nas narrativas imagens que animam uma memória que percorre e reconhece fontes d'água, espaços de trabalho, a casa de farinha, o forno, a trilha até a Ponta do Hospital, que já não pode mais ser percorrida.

Os sentidos do tempo são então correlacionados à enunciação de uma narrativa conjugada no pretérito, mas que se abre à expectativa de futuro, especialmente na pulsão de desejo em compartilhar as imagens que animam sua memória coletiva, e que constituem uma espécie de legado às novas gerações. Tal legado não significa a perpetuação de um tempo passado, imutável. Ao contrário, é cotidianamente reinventado e contado de outras formas. Trata-se de uma paisagem cultural em constante transformação.

Ao narrar a própria história, a Ponta Oeste reafirma sua sociabilidade e estabelece um contraponto às ações que visam ao seu desaparecimento: "Nós temos uma história de pesca, uma história de agricultura. Nós temos uma história...”. (Leonor Gomes Pereira, 2011).

A noção de memória coletiva representa um conceito de difícil apreensão. Ao mesmo tempo em que busca transmitir um sentido uniforme, sua elaboração é plural e multivocal, apresentada e enunciada por diferentes sujeitos e suas lembranças. 
No âmbito desta pluralidade é preciso considerar, ainda, a presença de narradores privilegiados, devido à sua posição social, resultante de fatores como idade, conhecimentos específicos, poder político, prestígio, entre outros. Um plano narrativo permite consolidar convergências e divergências entre lembranças individuais e familiares e as memórias coletivas, inerentes aos espaços de vida comum e seus temas associados.

A memória coletiva, no momento em que é narrada, constitui o que Walter Benjamin (1994) retrata pelo termo erfahrung, a experiência cujo sentido é socialmente compartilhado e que, no contexto de um coletivo social constrói uma temporalidade, uma duração e uma identidade.

Responsável por uma profícua via de interpretação da obra deste autor, Jeanne Marie Gagnebin (1993: 58) observa que erfahrung difere-se de erlebnis, ou seja, a experiência vivida, característica da individualidade centrada na expressão da subjetividade $^{8}$. Nos termos da autora:

(...) a filosofia da história de Benjamin inclui uma teoria da memória e da experiência, no sentido forte do termo (em alemão: Erfahrung), em oposição à experiência vivida individual (Erlebnis). O historiador materialista não pretende dar uma descrição do passado 'tal como ele ocorreu de fato'; pretende fazer emergir as esperanças não realizadas desse passado, inscrever em nosso presente seu apelo por um futuro diferente. Para fazer isso, é necessária a obtenção de uma experiência histórica capaz de estabelecer uma ligação entre esse passado submerso e o presente. Tal conceito de experiência (Erfahrung) tem, na teoria benjaminiana, uma origem literária: é tomado à procura proustiana e ao modelo na narração. (Gagnebin, 1993: 58).

A memória está correlacionada à identidade e, não lembrar de si mesmo, significa não saber mais quem se é, recaindo no anonimato. Sem memória não se consegue exercer a própria identidade. Entretanto, a identidade não pode ser substancializada, pois ela está ligada à história e à narração. Em outras palavras, a identidade é produto de uma narrativa de si mesmo, é construída seguindo as narrações

\footnotetext{
${ }^{8}$ De forma complementar, verifica-se que em sua acepção na língua alemã, erfahrung resulta de contração do verbo erfahren, traduzido como "chegar a saber"; ou ainda na qualidade de adjetivo que expressa as noções de "versado", "experto", "experimentado". Erfahrung é, por aproximação, a experiência em seu sentido coletivo, a qual pode ter um desdobramento empírico (erfahrungs). Por sua vez, erlebnis advém de erleben, ou seja, "viver", "presenciar", "assistir a", correlato a erfahren, "experimentar", "sofrer" ou "vivenciar". Desse modo, erlebnis significa simultaneamente "experiência", "a emoção causada pela experiência", a "vivência", em um sentido preponderantemente individual. (Hoepner et alii, 2001: 778 e 780).
} 
diversificadas que se faz na vida. Nesta via hermenêutica, é na produção narrativa que se definem os contornos da identidade.

Estudando o cotidiano e memórias de trabalho de mineiros em La GrandCombe, França, Cornélia Eckert observa que a inserção no mundo plural do mercado moderno, com o qual estes trabalhadores estavam confrontados, era acompanhada de “(...) outras totalizações que compartilham sensibilidades e projetos de vida, com que reconfiguram valores e lógicas de reinvenção do cotidiano". (Eckert, 2012: 23).

Em seu percurso metodológico, Eckert articula o tempo vivido e os testemunhos de vida destes trabalhadores com a constituição de um "sentido de durar no mundo". Nas palavras da autora:

(...) dimensionei sua maneira singular de viver e de pensar, o que é percebido na representação e na prática social intrinsecamente articulada. Busquei conhecer suas maneiras, ao mesmo tempo individuais e coletivas, de exprimirem as continuidades e descontinuidades de um tempo vivido, seus testemunhos sobre a vida em sociedade. Isto significa dizer que o sistema social é visto como um sistema de significações e a cultura como dimensão de um sistema de representações e de práticas sociais no qual se estabelecem as distinções e identificações na constituição de um sentido de durar no mundo. (Eckert, 2012: 23)

Memória e narrativa estão, assim, intimamente ligadas ao tempo e também à experiência. A noção de experiência introduz um fator de complexidade: envolve tanto uma faculdade geral de memória, perceptível na capacidade de lembrar, expressa nas imagens que retornam à memória, sob forma de "reminiscências", mas também diz respeito a uma faculdade de memória de natureza psicológica, que se refere à capacidade de lembrar e sua relação com as imagens mnêmicas, as quais paradoxalmente envolvem a um só tempo uma dimensão ativa, uma vontade de lembrar, e uma dimensão inativa, antes receptiva, quase um afeto (Benjamin, 1994).

O lembrar e o esquecer perpassam os sentidos da obra de Walter Benjamin. Interessa-lhe a natureza das imagens mnêmicas, o conteúdo lembrado e seu duplo, aquele que é esquecido. Imagens que vêm e afetam as pessoas, imagens que por vezes não se deseja lembrar. Por isso, em Walter Benjamin, a lembrança é paradoxal, na medida em que há uma atividade consciente do lembrar e ao mesmo tempo o afeto, como capacidade passiva diante das imagens.

As imagens recalcadas no inconsciente possuem uma faculdade de transformar o tempo presente. Para a psicanálise, ao se investigar a fundo camadas antigas da memória, serão reencontradas lembranças que pareciam apagadas, mas que estão vivas, 
ativas, possuem agência. Nesse sentido, a narrativa ligada a estas camadas profundas da memória pode despertar e revitalizar imagens, que recuperam poder de agência e, dialeticamente, se reposicionam na história.

\section{Tempo e espaço na Ponta Oeste da Ilha do Mel}

A coletividade da Ponta Oeste insere-se, por óbvio, num contexto atual das sociedades industriais. No entanto, sua narrativa aciona uma lógica de erfahrung, da ordem da tradição.

O envelhecimento da população residente, como vimos, é acompanhado de uma grande pulsão de vida, expressa na fabulação narrativa e que visa, em última instância, à manutenção dos elos com as novas gerações, inscritas no mercado de trabalho em Paranaguá, com as quais desejam tecer um horizonte de futuro e uma duração.

Os sentidos do tempo, do envelhecimento e da morte têm para Norbert Elias um valor heurístico quando o objetivo é estabelecer uma análise comparativa da experiência em sociedades tradicionais e modernas/industriais.

A experiência da modernidade, mediada fortemente pela noção de técnica, é para Elias de caráter individualizante. Nas sociedades industriais, nas palavras deste autor:

(...) as pessoas em geral se vêem como seres individuais, fundamentalmente independentes, como mônadas sem janelas, como "sujeitos" isolados, em relação aos quais o mundo inteiro, incluindo todas as outras pessoas, representa o "mundo externo". Seu "mundo interno", aparentemente é separado desse "mundo externo", e, portanto das outras pessoas, como que por um "muro invisível". (Elias, 2001: 61, grifos nossos)

Nessa leitura, o "muro invisível" que separa e isola a Ponta Oeste, imposto pela modernidade, e presente na narrativa comum dessa coletividade, revela uma imagem invertida de um tempo de grande visibilidade - tempo em que a Ponta Oeste recepcionava fluxos sociais relacionados às territorialidades de pessoas e famílias vinculadas aos territórios do Superagui, Cananéia, Bertioga, entre outros.

No contexto da Ilha do Mel, a Ponta Oeste é a porção de terras que se volta para dentro das baías, o que do ponto de vista dos fluxos sociais e ambientais traduz a condição de centralidade, revelada nos dados do cadastro produzido pelo Estado no ano de 1980 e reafirmada na memória oral. 
Observe-se que a Ilha do Mel, desde a cartografia colonial do século XVII, é compreendida como espaço estratégico devido à centralidade geográfica conferida por sua posição: situada entre as baías de Paranaguá e das Laranjeiras, abre-se para o mar.

No emaranhado de terras e águas, que configuram o território que se estende de Cananéia até o rio São Francisco, a Ponta Oeste da Ilha do Mel é o ponto extremo que se abre para o interior das baías, e oferece condições de repouso para embarcações que chegam de alto mar e para aquelas que se preparam para iniciar travessias de mais longa duração.

Esta posição estratégica já aparece bem representada, e com destaque, em cartografias coloniais. Em consulta ao acervo digital da Biblioteca Nacional, pudemos localizar a cartografia de João Teixera Albernaz - o moço, datada de 1666, na qual esta percepção estratégica da Ilha do Mel no território, então conhecido e nominado, fica evidenciada:

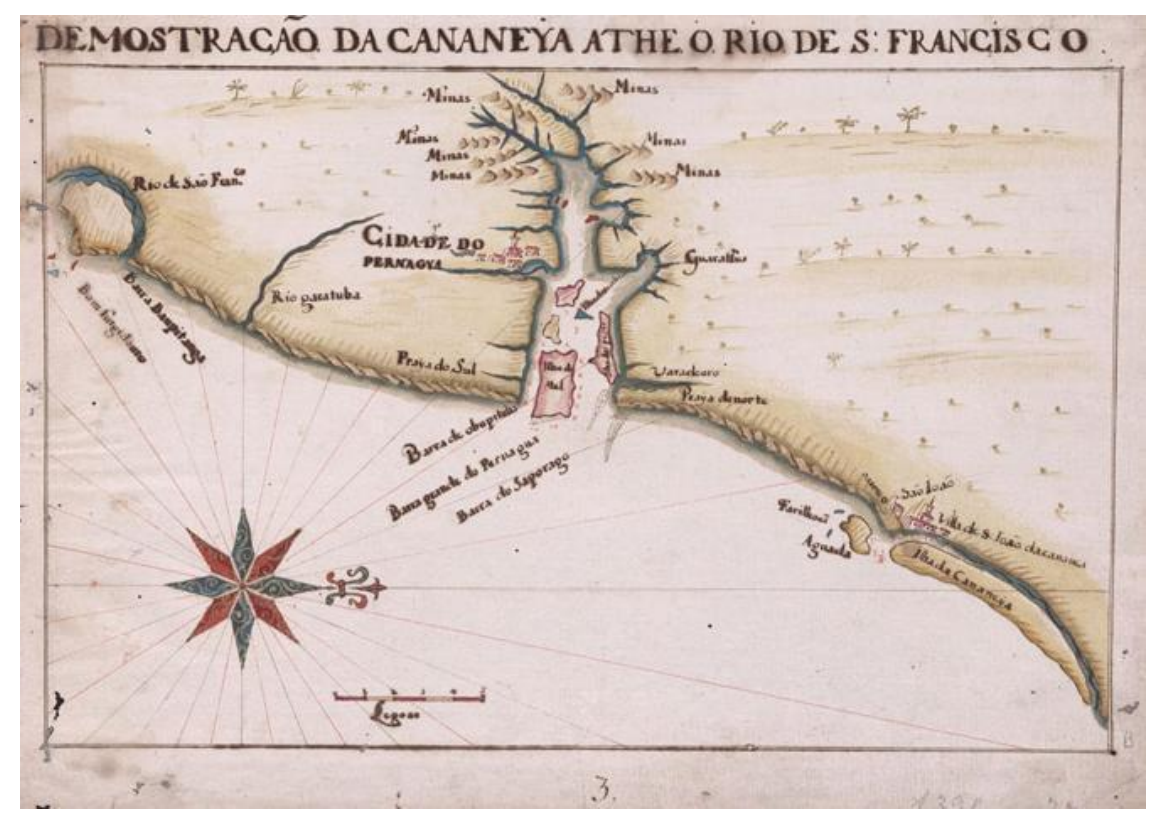

Figura 5: A Ilha do Mel na abertura das baías de Paranaguá e das Laranjeiras para o mar, assinalada com círculo sobre a cartografia de João Teixera Albernaz - o moço, datada de 1666.

Fonte: www.bndigital.br

Essa centralidade é ainda hoje visível nos dados expressos na figura 06, a seguir, que relaciona os atuais moradores da Ponta Oeste a suas localidades de nascimento: 


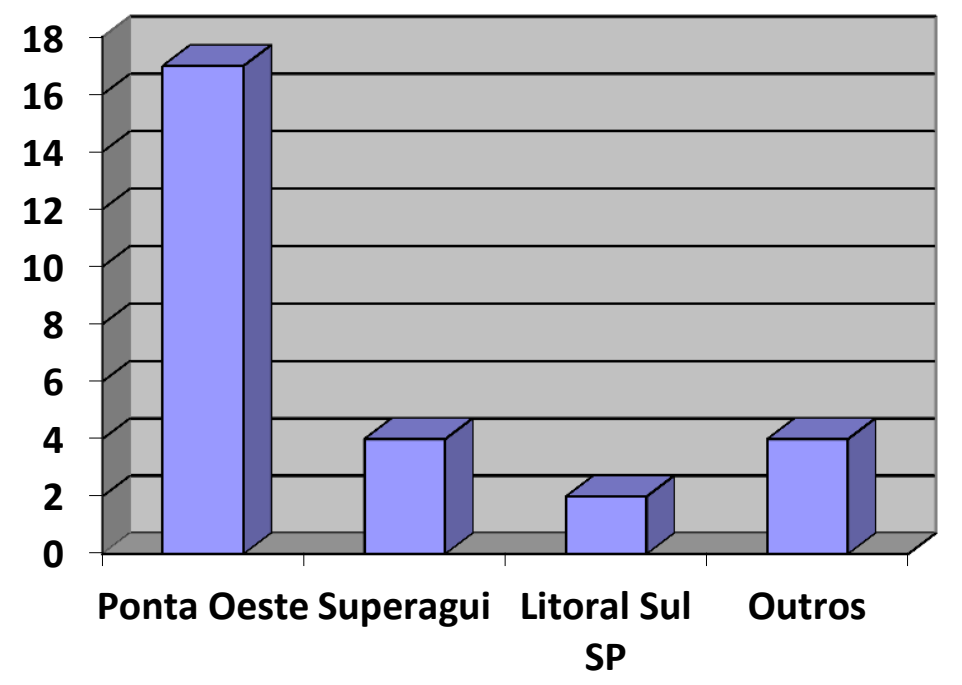

Legenda:

Ponta Oeste/Ilha do Mel - Baía de Paranaguá;

Superagüí - Baía das Laranjeiras;

Litoral Sul SP/Complexo Estuarino-Lagunar de Iguape-Cananéia-Paranaguá;

Outros: Encantadas/Ilha do Mel e Pontal do Sul.

Figura 6: Moradores da Ponta Oeste em relação ao local de nascimento (2011).

Embora a grande maioria dos 25 moradores da Ponta Oeste seja nativa do próprio local, as presenças marcantes de José Amalio (55 anos), nascido em Bertioga; de João Batista (75 anos), esposo de Maria das Neves Pereira Batista - referido respeitosamente como "professor" -, nascido em Superagui; de Lauro dos Santos Fernandes (65 anos), nascido em Cananéia; de Laurival Siqueira (62 anos), nascido na Praia Deserta/Superagui, esposo de Maria Mendonça Siqueira (59 anos), nascida na barra do Ararapira/Superagui e de Antonio Rodrigues dos Santos (67 anos), igualmente nascido em Superagui, são reveladoras da confluência inerente à posição estratégica da Ponta Oeste no Complexo Estuarino-Lagunar de Iguape-Cananéia-Paranaguá, um espaço agregador no circuito da pesca artesanal.

Como pontas de uma trama que pulsa na memória de seus protagonistas, a vida já não consegue atualizar as navegações memoráveis do passado. As rupturas e continuidades do pertencimento ao território são cotejadas com a sensibilidade de quem envelhece e quer transmitir às novas gerações sua própria narrativa, expressão da memória coletiva. 
Há incertezas com relação ao futuro, que corre o risco de perder seus elos com o presente. Como reconstituir um espaço-tempo permeado por fortes lembranças nas quais presente, futuro e passado se enlaçam? Como unir as pontas de um tempo que parece deslizar entre o narrar e o agir das pessoas da Ponta Oeste?

$\mathrm{O}$ ritmo das ondas do mar permite recordar o passado e olhar o futuro. No horizonte, grandes navios mercantes rumo ao porto de Paranaguá transpassam os múltiplos sentidos de uma pergunta que acompanha a experiência humana. Afinal, quem somos nós?

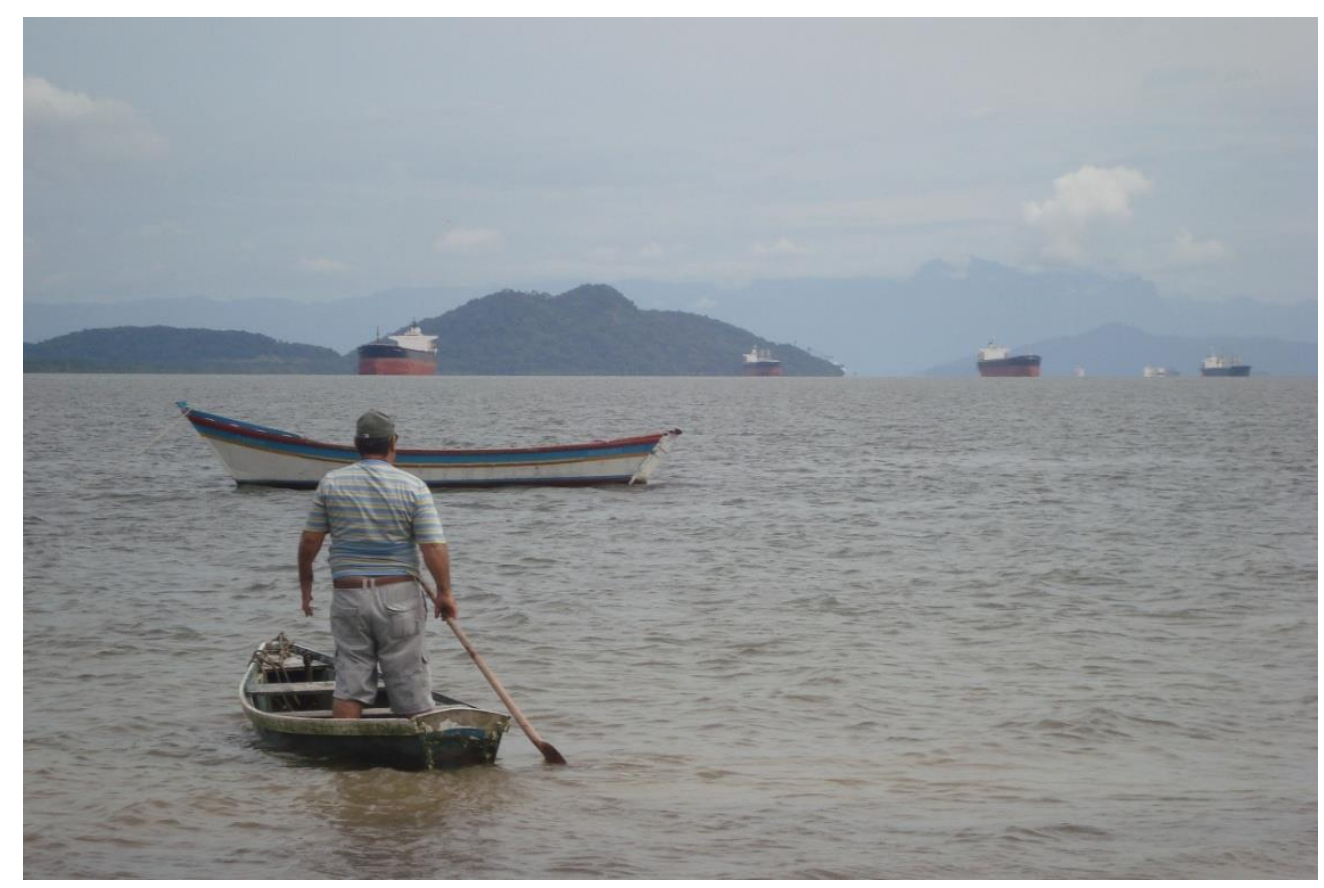

Figura 7: Zoel Pereira em sua canoa, de costas para a Ponta Oeste da Ilha do Mel, mira os navios de carga que trafegam na baía de Paranaguá.

Fotografia: Ana Elisa de Castro Freitas. 


\section{Referências}

BENJAMIN, Walter. Crítica da Violência - crítica do poder. In: BENJAMIN, Walter. Documentos de cultura, documentos de barbárie. São Paulo: CULTRIX/ Editora da Universidade de São Paulo, 1986.

. Magia e Técnica, Arte e Política: ensaios sobre literatura e história da cultura. $7^{\mathrm{a}}$. Ed. São Paulo: Brasiliense, 1994.

Teses sobre filosofia da história. In: KOTHE, Flávio (Org.) Walter Benjamin. 2. ed. São Paulo: Ática, p. 153-164, 1991.

DERRIDA, Jacques. Força de Lei: o fundamento místico da autoridade. São Paulo: Martins Fontes, 2010.

DIEGUES, Antonio Carlos. O Mito Moderno da Natureza Intocada. São Paulo: HUCITEC, 1996.

Enciclopédia Caiçara. Vol I. São Paulo: HUCITEC-NUPAUB, 2004.

ECKERT, Cornelia. Memória e Trabalho: Etnografia da duração de uma comunidade de mineiros de carvão (La Grand Combe, França). Curitiba: Appris, 2012.

ELIAS, Norbert. A solidão dos moribundos - seguido de envelhecer e morrer. Rio de Janeiro: Jorge Zahar Ed., 2001.

FOUCAULT, Michael. Em Defesa da Sociedade - curso no Collège de France (19751976). São Paulo: Martins Fontes, 1999.

FREITAS, Ana Elisa de Castro. A universidade entre os Mbyá Guarani: mediações para novos protocolos nas relações entre o Estado e os Povos Indígenas. In: UFPR. Livro de Resumos SIEPE. Curitiba: Pró-Reitoria de Extensão e Cultura, 2010.

GAGNEBIN, Jeanne Marie. Memória e libertação. In: . Walter Benjamin: os cacos da história. 2. ed. São Paulo: Brasilense, 1993.

HARDER, Eduardo. A situação dos direitos humanos na Comunidade da Ponta Oeste, Ilha do Mel. Relatório Técnico. Matinhos: UFPR/Litoral, 2007.

A Constitucionalização dos direitos culturais no Brasil e os sentidos de uma perspectiva patrimonial. 2014. Tese (Doutorado em Direito) - Programa de Pósgraduação em Direito, Universidade Federal do Paraná, Curitiba.

HOEPNER, Lutz; KOLLERT, Ana Maria Cortes; WEBER, Antje. Dicionário de bolso português: português-alemão, alemão-português. Berlin und München: Langenscheidt, 2001.

ITCF. Coletânea de legislação e documentação sobre a Ilha do Mel (1946-1985). Curitiba: ITCF, setembro de 1986.

LITTLE, Paul. Territórios Sociais e Povos Tradicionais no Brasil: por uma antropologia da territorialidade. Brasília: UnB, 2002.

PARANÁ. Plano de Manejo da Estação Ecológica da Ilha do Mel. Curitiba: Governo do Estado do Paraná, 2013.

ROCHA, Ana Luiza Carvalho da, e ECKERT, Cornélia. Etnografia da Duração antropologia das memórias coletivas em coleções etnográficas. Porto Alegre: Marcavisual, 2013.

Recebido em: 02/11/2015.

Aprovado em: 26/12/2015. 